\title{
El papel de supervisión del personal docente durante el desarrollo del recreo escolar
}

\section{The role of teacher's supervision during the development of school recess}

\author{
Jenny María Artavia-Granados ${ }^{1}$ \\ Universidad de Costa Rica, Sede Occidente \\ Departamento de Ciencias de la Educación \\ Alajuela, Costa Rica \\ jargra@gmail.com
}

Recibido: 4 enero 2013 Aceptado: 26 junio 2014 Corregido: 30 junio 2014

\begin{abstract}
Resumen: El recreo es un espacio escolar que procura alcanzar múltiples propósitos, entre otros: descanso y juego para los estudiantes, pero también, constituye una buena oportunidad para que los docentes observen los comportamientos y conductas que asumen sus estudiantes fuera del salón de clases. El proceso de supervisión del recreo por parte del personal docente y administrativo, resulta ser una tarea fundamental para lograr la prevención o solución de los conflictos que se puedan presentar durante este período escolar. Este artículo expone el desarrollo del proceso de supervisión del recreo escolar, que lleva a cabo el personal docente de una escuela de la Dirección Regional de Educación Occidente, a partir de los resultados obtenidos de una investigación de tipo cualitativa denominada "Juegos e interacción social en los recreos y su relación con los comportamientos violentos: El caso de las y los estudiantes de VI año de una escuela”. Entre los objetivos específicos, se procuró analizar el papel que desempeña el personal docente y administrativo, durante el desarrollo de los recreos. Ante el fenómeno de la violencia, la escuela tiene el compromiso social de brindar una solución pacífica a los conflictos que se puedan presentar. Sin embargo, como parte de las conclusiones obtenidas, se halló que el personal docente no asumió a cabalidad la supervisión del recreo, que la mayoría de docentes consideraron que no les correspondía supervisar, y que existen importantes diferencias entre la forma conceptualizar la supervisión del recreo por parte de la dirección del centro educativo y los docentes.
\end{abstract}

Palabras claves: Recreo escolar, disciplina escolar, supervisión del recreo escolar, violencia entre pares, resolución de conflictos.

Abstract: School recess is a space that tries to reach multiple purposes, among them: rest and play time for students; but, is also a good opportunity for teachers to observe student's behavior outside the classroom. School recess supervision by teachers and administrative staff turns out to be a fundamental task to achieve prevention or resolution of conflicts that may take place during this school period. This article outlines the development of monitoring the school playground or recess, carried out by teachers from a school at Dirección Regional de Occidente (Western Regional Bureau of Education). From a qualitative research called "Games and social interaction in recesses and its relationship with violent behaviors: the case of

1 Doctora en Educación de la Universidad Estatal a Distancia. Máster en Psicopedagogía de la Universidad Estatal a Distancia, Licenciada en Educación Primaria y en Administración Educativa, Universidad de Costa Rica, Docente del Departamento Ciencias de la Educación en la Sede de Occidente, Universidad de Costa Rica, Investigadora Instituto de Investigación en Educación, Universidad de Costa Rica. 
$6^{\text {th }}$ grade students." Its objectives, attempted to analyze the role of the teaching and administrative staff during school recesses. Facing the phenomenon of violence, the school has a social engagement to provide a peaceful solution to the conflicts that may arise. However, the findings show that teachers did not assume fully the supervision of recess, that the majority of teachers considered did not consider supervision as one of their duties, and that there are significant differences between the conceptualization of the school recess supervision by the principal's office and the teachers.

Key words: School recess. School discipline. Supervision of recess. Violence among peers. Conflict resolution.

\section{Introducción}

El recreo escolar es un espacio lúdico, el cual forma parte del espacio pedagógico que se desarrolla en la escuela y tiene como finalidad otorgar a los estudiantes el descanso necesario durante la jornada escolar, para lograr que el proceso de enseñanza y aprendizaje sea más productivo. Para la población estudiantil, el recreo resulta una actividad placentera y flexible, acorde con sus necesidades e intereses. En dicho espacio, los niños participan de actividades de juego espontáneas, las cuales permiten el movimiento libre, estimulan su imaginación, seguridad, competitividad, independencia, construcción, creatividad y obtienen la oportunidad de establecer relaciones interpersonales con otros compañeros.

Mantener relaciones interpersonales efectivas, resulta una tarea fundamental para la escuela. En el patio escolar, los estudiantes tienen la oportunidad de aprender y practicar habilidades sociales que van a favorecer la capacidad socializadora y autónoma del estudiante. Romera, Ortega y Monks (2008, p. 194) aducen que: "las vivencias que el grupo de iguales comparte y las convenciones y normas que entre ellos se generen van a incidir de manera decisiva en su desarrollo social". Asimismo, las autoras consideran que la cultura denominada "de iguales", se construye generalmente, con base en principios morales de respeto y compañerismo y da lugar a relaciones simétricas, las cuales van a influir de manera positiva en el desarrollo social, afectivo y cognitivo de las y los niños.

El recreo escolar es un espacio de tiempo, el cual la escuela organiza como parte del proceso educativo que desarrolla. En este, la escuela tiene la responsabilidad de velar por la integridad física y moral de la población estudiantil que acude a disfrutar en el patio, pasillos, gimnasios, canchas, entre otros espacios escolares empleados para disfrutar de este receso. Tanto el personal docente como administrativo, debe buscar -en consenso- las alternativas necesarias para lograr la supervisión de las diferentes actividades recreativas y de interacción personal, que se suscitan en el patio escolar.

Uno de los retos que enfrenta la escuela en la prevención de la violencia, es la forma de conceptualizar la función que debe cumplir el docente en la supervisión del recreo escolar. Según la National Asocciation for Sport and Physical Education citado por Chaves (2013), el recreo escolar debe ser supervisado por adultos, y estos deben intervenir cuando la seguridad física o emocional del niño o la niña estén en riesgo. Es necesario desde la organización escolar, contar con un proceso de coordinación, que permita la supervisión del recreo escolar por parte del personal docente y administrativo. Por tanto, resulta importante que desde la óptica del adulto, en este caso del docente, se tome en cuenta que las relaciones interpersonales que se desarrollan entre niños y niñas durante el recreo, precisan de una función supervisora que se perciba como una gestión que permita el acompañamiento del personal docente a la población estudiantil durante el recreo, en pro de interacciones sociales que tiendan a la convivencia pacífica. 
La escuela posee un compromiso en la formación de las nuevas generaciones y, por ello, es necesario que impulse el desarrollo de la dimensión moral primero en los docentes para que favorezca su propia conceptualización acerca de la importancia de desempeñar un papel más activo durante el recreo y que se proyecte positivamente en el comportamiento de las y los estudiantes, de manera que puedan convivir con los demás y participar activamente en la transformación social y cultural de la sociedad. Esta finalidad se podrá conseguir, como lo señala Torres (2006), si el profesional en educación tiene liderazgo moral y está comprometido con la construcción de valores. Pero para alcanzar esta meta, es fundamental que el docente asuma responsablemente y con un fuerte compromiso ético, la labor de formación integral de las y los estudiantes.

Según Artavia (2011) el docente del siglo XXI no puede, ni debe seguir pensando que la labor que lleva a cabo se circunscribe únicamente al trabajo de aula y de la institución educativa. Por eso, es necesario que amplíe el horizonte de la comprensión para que pueda vislumbrar el compromiso dentro del sistema educativo, y reconozca que el espacio laboral debe ser examinado desde perspectivas más interdisciplinarias. Es decir, un trabajo docente que, como lo indica Torres (2006, p. 81), sea contemplado "no como una serie de tareas que se pueden fragmentar sin mayores consecuencias, como un conjunto de actividades independientes entre sí, sino como algo integrado".

El ejercicio del docente en los salones de clase es una tarea que se ve sometida a presiones y tensiones, las cuales exigen de este profesional el despliegue de una serie de capacidades y habilidades que le permitan enfrentar y resolver el diario acontecer en el aula y en la institución educativa. Precisamente, una de las problemáticas que ha ido emergiendo con fuerza en el ámbito educativo y, por ende, en las preocupaciones del personal docente y administrativo que labora dichas instituciones, son los diferentes actos de violencia física, psicológica, verbal y de abuso sexual. Estos actos dificultan el proceso educativo, así como el desarrollo de una sana y pacífica convivencia escolar. Según Vernieri, la escuela requiere urgentemente brindar respuestas a la sociedad ante el fenómeno de la violencia, porque, "los conflictos en las escuelas siempre existieron, y la resolución violenta de ellos también. Quizás lo inédito o lo que nos sorprende actualmente son las formas en las que se resuelven y la edad de los niños que se ven involucrados en estos accionares violentos" (2010, p. 35).

La respuesta que dé la escuela ante la violencia manifiesta en el ámbito educativo, tiene que estar basada en procesos educativos que procuren la no violencia, por tanto, el proceso educativo que desarrolle la escuela deberá cimentarse en una educación que tenga como meta prioritaria, la prevención de la violencia a través de la construcción y promoción de los valores y la convivencia armónica entre los diferentes sujetos involucrados: estudiantes, personal docente y administrativo de la institución, padres de familia y otros miembros de la comunidad.

\section{La escuela ante la violencia escolar}

Actualmente, la sociedad está marcada por hechos de violencia que se suscitan diariamente en las calles, hogares y en la escuela, entre otros lugares. Desde la última década del siglo XX y hasta el año 2009, el incremento de la violencia en instituciones educativas de naciones como Estados Unidos y Argentina, comenzó a ser noticia, en los medios de comunicación masiva. 
Relatos sobre niños y jóvenes que, con armas escondidas en sus útiles escolares, dan muerte a compañeros, compañeras y docentes en las instalaciones educativas, se han convertido en noticia frecuente de medios televisivos y la prensa. Por otra parte, a nivel nacional, los periódicos se han encargado de informar a la sociedad costarricense acerca del aumento de la violencia en el interior de nuestras instituciones educativas. Las noticias informan a la ciudadanía acontecimientos violentos donde niños y jóvenes son partícipes de riñas, en donde se hace uso de armas blancas y de fuego contra compañeros e inclusive contra el personal docente y administrativo. Este tipo de acontecimientos, han permitido a la ciudadanía tomar conciencia de que la violencia también ha ingresado al interior de las instituciones educativas.

Desde el panorama de violencia que sacude a la sociedad, la escuela es visualizada como la institución social que, por antonomasia, está llamada a fomentar una educación para la paz. Esta educación debe estar caracterizada por la implementación de procesos educativos que procuren la formación de un ciudadano autónomo, con valores cívicos como: autonomía, solidaridad y equidad; así como valores morales: responsabilidad, honestidad, equidad, respeto, tolerancia, lealtad (Artavia, 2011). De modo que, estos valores le permitan asumir el compromiso, la responsabilidad y el derecho que tiene toda persona de vivir en una sociedad sin divisiones, exclusiones, ni violencia. Precisamente ante este reto, el Ministerio de Educación Pública, ha impulsado el desarrollo de los temas transversales en el trabajo de aula, los cuales tienen como eje principal el desarrollo de valores y actitudes que permitan el desarrollo integral de niños y jóvenes en contextos de sana convivencia.

Autores como Brawer (2006) y Osorio (2006), nos recuerdan que la violencia presente en las instituciones escolares se debe analizar desde dos perspectivas a saber: la violencia que ingresa a la escuela producto de factores externos de índole social, económica, familiar, cultural, los cuales se desarrollan en la sociedad; y la violencia que surge desde lo interno de la escuela, como producto de aspectos relacionados con: los roles entre estudiantes y docentes basados en relaciones de poder de dominio y control, las dimensiones de la escuela y la cantidad de estudiantes, las pugnas de poder entre el personal docente y administrativo, entre otros. A partir de esta perspectiva, el papel de la escuela ante el fenómeno de la violencia, se torna complicado. Al respecto Arellano (2007), manifiesta que se suele observar un sistema educativo con estructuras estereotipadas, que parece no poder dar respuestas a esta problemática y que por ende se le dificulta "formar ciudadanos que dialoguen y trabajen en escenarios enmarcados en una cultura de paz, que piensen y actúen considerando la vida en común y el bienestar colectivo". (2007, p. 24)

La escuela no puede permanecer neutral ni ajena, ante el fenómeno de la violencia. Por el contrario, tal y como lo indica Artavia (2011), está llamada a promover un proceso de resolución de conflictos que procure la prevención de la violencia. Barreiro (2010) manifiesta que existen dos formas de enfrentar las situaciones conflictivas que se desarrollan en las instituciones educativas. Al respecto enuncia la existencia de un paradigma punitivo, el cual enfatiza en el castigo o sanción cuando se viola una norma; y otro, que acentúa la posibilidad de prevenir los conflictos tratando de entender la lógica de su funcionamiento.

La misma autora indica que, el primer paradigma es normativo, individualista y punitivo, mientras que el otro es comprensivo, humanista e integral. Según Barreiro (2010) en 
el modelo punitivo, el docente es quien ejerce la autoridad y las normas que se deben cumplir son dictadas por la institución educativa. Este modelo permite identificar el o los culpables y aplica la sanción como castigo ante el comportamiento incorrecto. El modelo comprensivo, humanista e integral se presenta como una alternativa diferente, la cual procura lograr un clima de trabajo o grupal a través de acciones que intenten comprender el porqué de los conflictos o comportamientos violentos, impulsa procesos de comunicación fluida entre las partes que enfrentan la problemática. Con estos modelos, como lo indica Barreiro (2010, p. 46), se educa desde la perspectiva punitiva para "el disciplinamiento; porque dentro de esta concepción, educar es enderezar, corregir, "poner en el molde"; mientras que, el modelo comprensivo, humanista e integral se halla asociado con una mirada más humanística; educar es una forma de ayudar o estimular el crecimiento personal."

Desde la perspectiva que presenta Barreiro, se podría entonces manifestar que el modelo comprensivo, humanista e integral busca la prevención de la violencia escolar, así como la construcción y el desarrollo de procesos de convivencia pacífica, los cuales procuren una mejor organización del centro escolar, a través de acciones que: logren la participación de todos los integrantes del ámbito escolar; la construcción y, por ende, el cumplimiento de las normas establecidas por todas las partes que la conforman; la construcción de procesos de comunicación que permitan el mejoramiento de las relaciones interpersonales entre estudiantes, padres de familia, docentes y personal administrativo; así como, el desarrollo continuo de procesos axiológicos que permitan la formación integral de la población estudiantil y de sus familias. (Artavia, 2011)

\section{El docente ante la violencia escolar}

En el ámbito escolar, el docente cumple el papel de mediador o mediadora ante los comportamientos violentos que se suscitan entre las y los estudiantes, para ello, procura enfrentar esta problemática a través del desarrollo de diversos modelos disciplinarios, los cuales le permitan dar resolución a las situaciones conflictivas y violentas que se presentan en la escuela.

Para Artavia (2011), generalmente, el docente tiende a emplear el modelo punitivo el cual establece una sanción ante una acción tipificada en las normas de convivencia de la escuela, como una falta. Este modelo enfatiza en el castigo que requiere el infractor y no permite, por tanto, la reconciliación entre las partes. Asimismo, el docente hace uso de otro modelo denominado relacional, el cual según Torrego (2006) procura la resolución del problema de violencia a través de la relación directa entre las partes involucradas. Este modelo procura solucionar la problemática a través del diálogo y la reconciliación entre las partes y desde esta perspectiva, la víctima es restituida de manera moral o material y el victimario puede liberar su culpa, lográndose por tanto la reparación del daño y la reconciliación entre las partes.

Estos dos modelos emergen como mecanismos que actúan sobre la falta cometida, pero no proveen al centro educativo de un proceso de prevención de la violencia, así como de convivencia pacífica. Torrego (2006) manifiesta que, resulta muy importante que el docente se dé a la tarea de desarrollar un modelo integrado de mejora de la convivencia, a través de procesos que mejoren el desarrollo del currículo escolar, tras la búsqueda de 
procesos educativos más inclusivos y democráticos y el tratamiento de medidas organizativas relacionadas con el mejoramiento de la convivencia.

\section{El docente y la función de la supervisión, en pro de la prevención y la sana convivencia escolar}

El docente está llamado a supervisar el proceso educativo que se implementa en el salón de clases, el comedor, el patio de juegos, entre otros espacios de la escuela. La supervisión es un proceso mediante el cual el docente tiene la oportunidad de desarrollar ciertas habilidades y destrezas, que le permitan conocer y mejorar el desarrollo intelectual, personal y social de las y los estudiantes, en el desarrollo del proceso educativo, que se lleva a cabo en un salón de clases y en cada uno de los espacios de la escuela, en general.

Según el Programa de capacitación para administradores de la educación, del Ministerio de Educación Pública (1991), existen diferentes estilos de supervisión, los cuales se citan a continuación:

- Supervisión correctiva: Es un tipo de supervisión autoritaria, que procura encontrar la problemática para darle corrección. No se interesa por indagar las causas de los problemas.

- Supervisión preventiva: Pretende evitar los problemas antes de que aparezcan. Da confianza a docentes y estudiantes.

- Supervisión creativa: Intenta estimular y orientar la búsqueda creativa de la solución de los problemas. Promueve la cooperación entre las partes involucradas.

- Supervisión que deja hacer y deja pasar: Es un estilo de supervisión pasiva, con escasa responsabilidad y que enfatiza en lo individual.

- Supervisión paternalista: Suscita el desarrollo de un estilo basado en la "amistad", se procura obtener resultados inmediatos y no a largo plazo o duraderos. El comportamiento grupal se enfatiza en los deberes y privilegios, y no en la armonía y cohesión del grupo.

- Supervisión moderna o democrática: Este estilo de supervisión hace énfasis en la valoración del individuo como tal y la importancia del trabajo cooperativo. Le da importancia a la solidaridad y responsabilidad que asume cada miembro de un grupo.

La supervisión, por tanto, es una actividad que permite analizar los acontecimientos que se suscitan en la vida cotidiana de un salón de clases, o de cada uno de los espacios físicos que conforman una institución educativa. Por tanto, los resultados que se logren alcanzar de este proceso, redundan en consecuencias positivas para el desarrollo integral de las personas que conforman la institución, así como en aspectos positivos en pro del desarrollo del proceso educativo que se implementa en el centro educativo.

La supervisión resulta entonces un proceso fundamental para el logro de la prevención y la convivencia escolar, porque permite al docente y al personal administrativo de un centro educativo explorar e implementar aquellas acciones tendientes al desarrollo de actitudes favorables a la convivencia pacífica entre estudiantes, y personal docente y 
administrativo y estudiantes. Asimismo, accede a la búsqueda constante de acciones que procuren medidas sistemáticas individuales y grupales, cuya finalidad sea la prevención de comportamientos violentos entre estudiantes. (Artavia, p. 150, 2011)

\section{En la escuela objeto de estudio: ¿Cuál es el papel que cumple el personal docente y administrativo durante el desarrollo de los recreos?}

En el estudio se procuró comprender cómo los juegos y las interacciones sociales de las y los estudiantes de VI año, durante los recreos se relaciona con los comportamientos violentos que se desarrollan en esta institución educativa. Uno de los objetivos específicos de la investigación, fue describir el papel que desempeña el personal docente y administrativo durante el desarrollo de los recreos. Precisamente, la información que se obtuvo a partir de este objetivo, es la que sustenta este artículo.

La metodología cualitativa con la cual se desarrolló la investigación, accedió, a través del empleo de técnicas de recolección de datos como la observación participante, los grupos focales y las entrevistas en profundidad, descubrir, analizar y comprender los datos que aparecieron durante el avance del estudio. El empleo de este tipo de técnicas facilitó a la investigadora penetrar en el proceso de juego e interacción social, que llevaron a cabo niños y niñas en el recreo. Este proceso de investigación permitió conocer los escenarios donde niños y niñas se movilizaron durante el tiempo de los recreos, identificando cuáles eran los juegos y las interacciones sociales más frecuentes entre ellos. Asimismo, se pudo reconocer los comportamientos violentos que propiciaron los juegos y las interacciones sociales dadas en ese momento escolar. También fue posible a través de la técnica de observación, identificar el rol de supervisión que llevó a cabo el personal docente y administrativo, en el desarrollo de los recreos. En el proceso de observación, la investigadora junto con dos asistentes estuvo presente en el desarrollo de cincuenta recreos, hicieron uso de una crónica diaria, la cual permitió realizar anotaciones que describieron minuciosamente los acontecimientos suscitados entre las y los estudiantes y el papel que jugó el personal docente en la supervisión, durante el período de los recreos. Una vez concluido cada proceso de observación, la investigadora y los asistentes implementaron el proceso de triangulación de los datos producto del trabajo de campo. Igualmente, los datos recolectados a partir de las entrevistas en profundidad y los grupos focales, fueron interpretados y analizados rigurosamente. La investigadora logró conocer la realidad que se vivió en los recreos de la escuela en estudio, mediante los procesos de interpretación y comparación de los datos; es decir a través de la triangulación y el análisis de la información obtenida en el trabajo de campo.

Las principales fuentes de información estuvieron conformadas por la directora de la institución, las y los docentes que imparten lecciones al VI año en la escuela en estudio, las docentes que laboran con los otros sextos grados, así como los treinta y dos estudiantes que constituyen el grupo. Para mantener la confidencialidad y anonimato de los datos externados por las y los participantes en la investigación, se procedió a identificar a los sujetos del estudio con nombres ficticios.

Una de las categorías analizadas en esta investigación, fue precisamente el rol del personal docente y administrativo durante el desarrollo de los recreos en la escuela en estudio. Las subcategorías que se tomaron en cuenta, fueron las siguientes: 
- Presencia del personal docente y administrativo en el recreo escolar.

- Función que cumple el personal docente y administrativo de la escuela, durante el desarrollo del recreo.

- Acciones que lleva a cabo el personal docente y administrativo, cuando se suscitan comportamientos violentos en los recreos.

- Tipo de organización empleada por la escuela para la supervisión del recreo.

- Tipo de medidas adoptadas por la escuela para resolver comportamientos violentos entre estudiantes, durante los recreos.

La supervisión es una función inherente a la labor que desempeña el docente en la institución educativa, la cual resulta ser muy importante para el buen desarrollo del proceso educativo. El docente implementa cotidianamente la labor de supervisión en el aula del proceso de enseñanza y aprendizaje, en la que participan sus estudiantes. Pero, también está llamado a supervisar el espacio empleado para el recreo. Esto porque, tanto al personal docente como el administrativo, tienen la obligación de velar por la protección integral (física, moral e intelectual) de las y los estudiantes que están bajo su custodia, mientras permanezcan en el centro educativo, ya sea en el período de clase o en el recreo.

\section{a) Presencia y funciones del docente y administrativo durante el recreo escolar}

La presencia del docente, durante el desarrollo de los recreos, resulta fundamental; especialmente, si esta participación va más allá de la función de vigilancia y se convierte en un proceso donde docente y estudiantes interactúan; donde el educador colabora en la conducción y resolución de los conflictos que se pueden suscitar; así como la participación del docente en los juegos que desarrollan sus estudiantes. Las y los estudiantes necesitan sentir el apoyo del docente, cuando las circunstancias lo ameriten. Precisan sentir una actitud de acompañamiento en aquellas actividades que desarrollan durante el recreo. En el grupo focal, se les preguntó a las y los estudiantes si les agradaba que las y los docentes estuvieran presentes en los recreos. A esta interrogante contestaron:

Sonia: No me gustaría, porque a veces uno está hablando de algo vacilón y la profe se pone a escuchar y a uno le incomoda que esté ahí, escuchando, y lo que uno está haciendo.

Patricia: A veces sí, porque uno va caminando y lo golpean y, a veces, dicen que es culpa de uno, y si la profe está cerca ella ve y ayuda.

Luisa: ¡Bueno!, sí, a veces; porque lo están vigilando y uno sabe que no tiene que hacer nada malo. Entonces, uno sabe que no tiene que hacer nada.

De las respuestas dadas por las y los estudiantes, se puede reconocer que - para estos- la presencia del personal docente en los recreos es sinónimo de alguien que vigila, y por ende, regaña. Al parecer, sienten que su presencia no les permite tener la privacidad deseada por ellas y ellos, en las actividades que desarrollan en los recreos. En las respuestas también 
se logra identificar que "a veces" les conviene que las y los docentes estén presentes, porque pareciera que su presencia es necesaria cuando se presenta algún conflicto entre estudiantes, para que logre observar quién o quiénes son los causantes o, también, para recordarles -con su sola presencia- que tienen que tener un buen comportamiento durante el recreo.

\section{b) Tipo de organización empleada por la escuela para la supervisión del recreo}

Toda institución educativa es una organización social que se desarrolla en un período histórico determinado y dentro de una comunidad específica. Esta cumple -a su vez- funciones particulares, en escenarios particulares y donde cada uno de los miembros que la conforman cumplen roles y competencias profesionales específicas. La función principal, que cumple una institución educativa, es la formación integral de las y los estudiantes que tiene a su cargo; así como la proyección de la labor académica, hacia la comunidad donde está inmersa. Para lograr estos objetivos, la escuela debe impulsar una organización que tome en cuenta, tanto el aspecto físicoestructural, como el recurso humano. En la organización física de la institución, se deben tomar en cuenta todos los espacios físicos, como: aulas, biblioteca, sala de profesores, comedor y patio de recreo. Estos espacios cumplen una función en el desempeño de los roles y responsabilidades que asume el recurso humano, conformado por estudiantes y personal docente y administrativo.

Resulta importante, desde la organización de una escuela, contar con un proceso de coordinación, que permita la supervisión del recreo escolar por parte del personal docente y administrativo. Olweus (1998) hace referencia a que, en el estudio de Bergen, se logró observar que ante una mayor presencia de profesores que vigilaban el recreo, era menor la cantidad de problemas de agresión que se presentaban en la escuela. Por ende el propio Olweus (1998, p. 44) manifiesta que: "este resultado pone de manifiesto la gran importancia de disponer de un número suficiente de adultos presentes entre los alumnos durante los períodos de descanso". Esto por cuanto resulta importante que el personal docente esté dispuesto a intervenir, en caso de que se susciten comportamientos violentos entre las y los estudiantes o posibles accidentes.

En las observaciones realizadas se pudo constatar que la supervisión del recreo por parte de las y los docentes, resulta ser un proceso que no se cumple a cabalidad por parte de todos los miembros del personal docente. Se citan a continuación algunos de los ejemplos de las observaciones realizadas, que permiten confirmar la aseveración realizada anteriormente.

Las docentes se mantienen vigilantes en las áreas asignadas: pasillos, cancha, gimnasio. Sin embargo, se distraen conversando, revisando cuadernos y tomando café. (Observación día 28 de mayo de 2010)

Hoy la directora recorría los pasillos observando las actividades que realizaban los niños, llamando la atención y conversando con algunos niños. Las docentes también se mostraban atentas en la supervisión del recreo. (Observación día 3 de junio de 2010) El día de hoy las docentes están supervisando en los pasillos, al concluir el recreo un niño le pegó un manotazo a una compañera delante de la docente y esta no hizo nada al respecto. (Observación día 9 de junio de 2010)

La supervisión del recreo es una función que debe cumplir el docente tal y como se estipula en diferentes leyes y normativas, pero también es un proceso de acompañamiento del 
estudiante por parte del docente, donde ambos logren disfrutar de ese período de tiempo a través de actividades donde puedan integrarse y compartir algunos de los juegos, conversar, merendar juntos, entre otros. Vista desde esta perspectiva la integración del docente al recreo permite que a través de procesos de convivencia cotidiana en las diferentes actividades que se programen o emerjan, se faciliten las relaciones cordiales entre los miembros de la comunidad educativa y por ende la supervisión del recreo se torne un proceso continuo y dinámico. $\mathrm{Al}$ revisar las observaciones realizadas se pueden percibir que existen diferentes percepciones y actitudes por parte del personal docente acerca del proceso de supervisión del recreo. En primera instancia la lectura que se puede realizar de los hechos observados permite reconocer que la mayoría de las y los docentes están ahí físicamente ubicados en los sectores de la escuela que la dirección les asignó, pero que realmente no se está cumpliendo a cabalidad con el proceso de supervisar las actividades y juegos que desarrollan las y los estudiantes en el recreo. El personal docente aprovecha el lapso del recreo para realizar otro tipo de actividades y no prestan atención a lo que realmente sucede en el espacio físico destinado para que la población estudiantil comparta el recreo.

Como parte de este proceso de investigación también se procedió a preguntar al personal docente y administrativo, acerca de si la escuela tiene el personal docente organizado para la supervisión del recreo, ante lo cual sus respuestas fueron las siguientes:

Docente Marta: Sí, lo que es para cuidado de recreos por supuesto que sí, eso desde que yo llegué aquí y en todas las instituciones en las que he trabajado se dice que sí, o sea que cada docente tiene repartido su corredor y los tiempos, si la directora siempre ha insistido en eso y siempre ha hecho por ejemplo un cuadro que cada docente va a cuidar en los recreos y cuáles corredores les toca.

Docente Juliana: Bueno, cada docente cuida el pabellón donde le corresponde y los especiales cuidamos el gimnasio.

Docente Roque: Sí, aquí la señora directora nos ha hecho conciencia de cuidar por pabellones o distintas zonas de la institución, la forma es cuidar de que los niños no estén subidos o no estén tomando o cogiendo cosas que pueden provocar algún tipo de accidente.

Al revisar las respuestas de las y los docentes se logra identificar que la escuela sí cuenta con una organización para la supervisión del recreo, y que en la misma todo el personal docente es distribuido por sectores para cumplir con la vigilancia de las actividades que desarrolla la población estudiantil durante el recreo. Sin embargo, es importante señalar que algunas de las docentes entrevistadas manifiestan que se suscitan dos situaciones que entorpecen el proceso de supervisión del recreo, por un lado parece que no todo el personal docente cumple con las indicaciones de supervisión dadas por la directora, y el otro aspecto es el relacionado con las llamadas de atención que realizan las y los docentes a estudiantes que no son los de su grupo y que por tanto no son atendidas por estos. Esta situación pareciera ser que se genera a partir de la ausencia de un proceso de comunicación continua, donde la población estudiantil de la escuela sea informada acerca del desarrollo de la supervisión del recreo. Cuando las y los estudiantes tengan claridad de que la autoridad durante el 
desarrollo del recreo la ejerce todo el personal docente, probablemente este tipo de situaciones problemáticas desaparecerán. Porque como lo señalan Carbonell y Peña (2001, p. 94), "el modelo de organización del centro educativo puede ser otro de los principales factores determinantes del deterioro de la convivencia en los centros, ya que estos, como toda organización social, precisan adaptarse a los tiempos y las circunstancias personales y concretas de sus componentes". Así entonces, es preciso que la organización de la supervisión del recreo escolar sea un proceso conocido y aceptado por las y los estudiantes.

La señora directora respecto a la organización de la escuela para la supervisión de los recreos, mencionó que:

Bueno, lo hemos hecho de una y otra forma, a principios de año se ha hecho por horarios, se le dice que en tal corredor le corresponde a tal profesor, que a tal horario le corresponde a tales profesores, pero cuesta mucho, porque el docente cree que es un derecho adquirido que ellos tenían que los recreos eran para ellos.

Al leer el argumento dado por la administradora de la escuela se puede identificar que realmente existe una organización de la supervisión del recreo, pero existe una resistencia por parte del personal docente para llevar a cabo dicha función. En las observaciones realizadas se pudo reconocer que algunas de las docentes se mantenían en los recreos, pero básicamente estaban conversando y tomando café. Inclusive el sector donde más se pudo observar a las docentes fue en el pasillo contiguo a la soda, ahí conversaban y merendaban mientras recurría el recreo. Otras docentes permanecían en sus aulas o sacando fotocopias en un espacio físico destinado para tal fin y que se ubica contiguo a la dirección y por tanto, estaban ajenas a lo que estaba ocurriendo en los recreos. Algunas docentes, pero muy pocas en realidad se daban a la tarea de supervisar a la población estudiantil en los juegos y otras actividades recreativas, en los espacios asignados por la dirección. En muchas ocasiones se observó a la directora salir a recorrer los pasillos, la cancha de fútbol y el gimnasio, en este recorrido llamaba la atención a aquellos niños y niñas que estaban realizando alguna actividad peligrosa que podía generar un accidente, velando por el cuidado de las instalaciones de la escuela o simplemente conversando con algunos de las y los estudiantes.

\section{c) Tipo de medidas adoptadas por la escuela durante los recreos, para resolver comportamientos violentos entre estudiantes.}

Como parte del proceso de investigación resultó importante conocer qué medidas tenía adoptadas la escuela, para resolver los comportamientos violentos que se pudieran presentar entre las y los estudiantes durante el desarrollo del recreo. En primera instancia se trató de averiguar qué sucedía en la escuela y específicamente en los recreos, cuando se presentaban comportamientos violentos entre las y los estudiantes. Es entonces cuando en el grupo focal se procedió a preguntar a las y los niños si cuando se presenta algún problema durante el recreo, a quién o quiénes acudían, sus respuestas fueron las siguientes:

Verónica: A algún profesor o a nosotras mismas si le están pegando a alguien de nosotras mismas, sino a la profesora.

Investigadora: ¿Y por quéentre ustedes mismas se ayudan y no buscan ayuda de un o una docente? 
Karen: Porque tal vez no sea muy serio y entre nosotras lo podamos arreglar y si es más grande, acudimos a la ayuda de un profesor.

Mark: A un amigo o a la profesora.

Milena: A una amiga.

Investigadora: ¿Y por qué a una amiga y no a la profesora?

Milena: No sé, es que a veces si la cosa no es así tan seria, no hace falta la profe.

Juan Diego: Depende como sea porque si es jugando así, pero si no es jugando entonces si a la maestra. O a la profesora que esté más cerca.

Investigadora: ¿Y qué hace la docente?

Román: Manda reporte. Llama a la directora, si es muy grande.

Investigadora: ¿Y qué hace la docente?

Harold: Los separan y le avisan a la directora, entonces llaman a los papás.

Investigadora: ¿Qué hace la maestra cuando ustedes la llaman?

José María: Va a ver, a veces los separa o no hace nada o les manda reporte.

Sonia: Pero a veces no hace nada, porque según ella el problema no es tan importante y no hay testigos.

Ernesto: Porque hay algunos profesores que necesitan testigos para poder mandar reportes, entonces no los mandan.

Como complemento a la pregunta realizada a las y los estudiantes, se consultó al personal docente acerca de ¿cuáles son las principales quejas de los niños y las niñas en el desarrollo del recreo?, y en sus respuestas se hallaron básicamente tres tipos de quejas, una que tiene que ver básicamente con la duración del recreo, otra que hace referencia a los problemas de falta de espacio para jugar y la otra que acusa sobre los comportamientos violentos que se suscitan durante los recreos entre la población estudiantil entre los que destacan: empleo de malas palabras, apodos, empujones, zancadillas, golpes, entre otras manifestaciones de violencia. Según comentarios de las y los docentes este tipo de quejas es muy común que se dé durante el desarrollo de los recreos, porque en los espacios donde comparten las y los niños se congregan gran cantidad de estudiantes y por ende consideran es de esperar que se susciten situaciones conflictivas entre estos y por lo tanto las quejas se tornan en protestas cotidianas ante los problemas de espacio, tiempo y comportamientos antes citados.

En cuanto a las respuestas dadas por las y los estudiantes, estas permiten reconocer que algunas veces estos prefieren solicitar ayuda a un o una amiga si se presenta algún problema durante el recreo, antes que pedir la asistencia de la docente. Es importante retomar algunas de las respuestas de las y los chicos, especialmente aquella opinión donde señalan que sienten que la docente no hace nada o que requiere tener testigos para poder intervenir ante las situaciones problemáticas que viven en el recreo, esto permite reflexionar si realmente ellas y ellos sienten que el adulto es accesible ante sus requerimientos y si además podrá esperar una respuesta pronta y cumplida ante el conflicto que se presente. Al respecto Torrego (2006), enuncia que es importante que la escuela potencie el compromiso de 
toda la comunidad escolar a través de procesos de transformación de los conflictos, donde se procure una sana convivencia.

Se cita a continuación algunas de las respuestas dadas por las y los niños en el grupo focal, respecto a la siguiente pregunta:

Investigadora: En algún momento del recreo le han dado quejas a la maestra de lo que ocurre ¿qué ha hecho ella al respecto?

Kevin: Lo soluciona hablando con las dos personas u otra profesora.

Susana: Diay, habla con la persona que le ha hecho algo a uno, le mandan reporte.

Milena: Ella habla con la persona y si es preferible le manda el reporte.

Investigadora: ¿Qué labor les gustaría que hicieran las maestras durante los recreos?

Álvaro: Reunirse en la dirección, porque así llegan tarde después del recreo.

Estas respuestas permiten reflexionar en primera instancia que para estos cuando han dado alguna queja a las docentes, estas atienden la problemática conversando con los protagonistas del conflicto y que también realizan los reportes respectivos. Es importante recordar que la escuela debe efectuar procesos de intervención ante los conflictos y los problemas de violencia escolar, y estos podrían oscilar entre los modelos: punitivo, relacional e integrado. En el caso de la escuela objeto de estudio los modelos empleados por las y los docentes cuando se presentan problemas de violencia en los recreos, son el punitivo y el relacional; respecto al modelo punitivo Torrego (2006, p. 30) aduce que "se establece una sanción ante una acción considerada como alta y tipificada como tal en las normas de convivencia tanto las generales como las propias del centro," y por otra parte para este mismo autor, el modelo relacional "se centra en una resolución del conflicto a través de la relación directa entre las partes involucradas, es la búsqueda de una solución a través del diálogo por propia iniciativa entre las partes". (Torrego, 2006, p. 31) La escuela se debe abocar a la búsqueda constante de la resolución pacífica de los conflictos a través de procesos que conlleven justicia y serenidad entre la población estudiantil.

Es necesario analizar las respuestas dadas por las y los niños acerca de la siguiente pregunta: ¿qué labor les gustaría que realizara las maestras durante los recreos? Ante esta pregunta las respuestas evidencian que la mayoría de las y los estudiantes les gustaría que el personal docente no esté presentes en el recreo, porque pareciera que son percibidos como personas que obstaculizan e interfieren en las actividades que llevan a cabo. Inclusive una de las respuestas es bastante elocuente en su mensaje, porque Juan Diego menciona que cuando hay presencia de docentes en el recreo se siente encadenado, porque al parecer él siente que hay mucha vigilancia por parte del personal docente.

Siguiendo el tema de análisis se procedió a preguntarle a las docentes si cuando se presentan problemas de violencia en los recreos con el grupo en estudio, cómo abordaban la situación; sus respuestas fueron las siguientes.

Docente Roque: Si es la mayoría del grupo tengo que hablar con todo el grupo, si es una forma individualizada, pues llamo por aparte al estudiante o a la estudiante y trato de resolver de esa forma, entonces depende de cómo se presenta la situación.

Docente Cristina: Bueno yo por lo general los traigo al aula y hablo con ellos, sino es 
nada serio lo trato de arreglar yo, y si es algo que se va de mis manos busco apoyo en la dirección.

Docente Etilma: Cuando yo comprobaba que habian golpeado a algún niño, porque habian golpes también, entonces tenía que escribir lo que aquí llamamos una boleta para los padres y bajando los correspondientes puntos.

El abordaje que lleva a cabo el personal docente del fenómeno de la violencia que se suscita entre estudiantes durante los recreos, es un proceso donde se tiende a la resolución a través del diálogo entre las partes: víctimas y victimarios; esto permite como bien los señala Torrego (2006), que la víctima sea restituida material o moralmente ante el hecho vivido y al agresor lo libera de su culpa. Por otra parte, se identifica que si este tipo de modelo de resolución de conflictos no resulta o si el problema de violencia que se suscitó es muy complejo, la o el docente tiende al empleo de la boleta. Este proceso es totalmente punitivo y con este se pretende sancionar la acción que es tipificada como incorrecta.

Ante las respuestas dadas por las y los docentes se procedió a preguntarles si ¿consideraban que la sanción que se aplica en los recreos es una forma adecuada para controlar los hechos de violencia?, a lo que contestaron:

Docente Roque: No eso es una medida temporal para mí, para mi concepto es una medida temporal porque la violencia es algo que ya el niño la trae, digamos ya es algo que se ha formado y se ha creado desgraciadamente en el hogar, o sea si en el hogar el niño ve de una u otra forma violencia, ya está creada y manifestada, ya en la institución lo que uno hace es tratar de frenar, eso para que no afecte a los demás compañeros de la población estudiantil, pero considero que es una medida temporal.

Docente Leonor: Es que si yo le bajo a un chiquito 30 puntos que es lo que está establecido por faltas graves, no beneficio ningún aspecto considero yo, primero porque el niño no logra asimilar, comprender qué pierde a nivel académico, pero sería más provechoso que el docente busque un mecanismo donde los haga asimilar, que él vea por qué razones esa acción es inadecuada y qué valore la importancia de pensar antes de actuar.

Respecto al empleo de sanciones que se otorgan por los hechos de violencia en los recreos, la directora manifestó que:

Mandar el informe o la boleta al hogar es lo que tenemos, es la única herramienta que nos está dando el Ministerio de Educación Pública, el reglamento de Evaluación de los aprendizajes y de conducta, pero al mismo tiempo nos dice que ningún niño pasa por conducta, yo no sé qué creer, qué función tiene.

La boleta como bien se tipificó anteriormente, obedece a la implementación de un modelo punitivo empleado para lograr la resolución de los conflictos en el centro educativo. Como bien se puede identificar el personal de la escuela objeto de estudio hace uso de la boleta, como un recurso que permite tratar de dar solución a una problemática que para el docente es considera como compleja, quizá difícil de ser enfrentada y por ende encuentran que el reglamento es un instrumento que permite de forma fácil y obligada la resolución de los problemas que se podrían enfrentar. Para Carbonell y Peña (2001, p. 31), "las soluciones de carácter reglamentista 
en algunos momentos y contextos son buenos, pero su abuso conduce, normalmente, a un estado de incumplimiento generalizado y a lo más grave que suele ser al reto, como meta del incumplimiento". Esta situación que hacen referencia los autores, se logró percibir en algunas de las observaciones realizadas donde las y los estudiantes les asustaba la idea de que el o la docente les enviaran una boleta, por estar realizando algo incorrecto en el recreo, pero luego entre ellos se daban comentarios del no cumplimiento de la sentencia. Un hecho que ejemplifica el incumplimiento de la amenaza del envío de una boleta se suscitó cuando:

Kevin corre rápido por el pasillo se topa con una compañera la empuja ella cae al suelo, él sigue corriendo y empuja a la docente Marta (docente de cómputo) ella molesta le llama la atención y Kevin le contesta que para que estaba estorbando. La docente lo regaña y le dice que le va a enviar una boleta, el niño casi llorando se disculpa con ella y le pide que no le haga la boleta, a lo que la docente se niega. Kevin se va hacia un rincón muy triste, y de pronto llega Andy y le dice: "mae no se agüeve, a la profe todo se le olvida y va a ver no le va a mandar boleta". Kevin se siente mejor y corre atrás de Andy por el pasillo. (Observación realizada el día 13 de setiembre de 2010)

Como se puede inferir de la situación observada en ese recreo, algunos niños realmente temen a la boleta, pero otros han percibido que a veces el docente amenaza con el envío de una boleta, pero no cumple con lo estipulado como parte de la sanción. Por ende, la gestión del docente ante los comportamientos violentos que se puedan suscitar en el centro educativo, resulta ser inoperante puesto que no es capaz de dar una respuesta adecuada y eficaz ante la problemática de la violencia escolar.

Sin embargo, el proceso de supervisión que pueda llevar a cabo el docente durante el desarrollo de los recreos escolares, será siempre una acción necesaria, la cual permita el acompañamiento por parte del adulto a niñas y niños que juegan y se interrelaciona socialmente con sus pares. En ese proceso de acompañamiento, se pueden suscitar acciones que van desde el compartir juegos y conversaciones entre docentes y estudiantes, hasta la vigilancia de aquellos comportamientos entre estudiantes, que muestren tendencias a la violencia física, verbal, psicológica o de acoso sexual. Para Olweus (1998), es indispensable que la escuela tenga presencia de profesores durante el recreo, porque así se produce una cantidad menor de agresiones entre estudiantes. Al respecto, el autor señala que es importante que en los espacios externos exista un número adecuado de adultos que estén junto a los estudiantes en el período del recreo y que la escuela disponga de un plan de vigilancia.

Asimismo, Blaya, del Observatorio Europeo de Violencia Escolar citada por Dean (1995), considera oportuna y necesaria la vigilancia estricta en aquellas zonas comunes de la escuela, como son: el patio y los pasillos, donde se podrían suscitar comportamientos violentos. Durante el recreo escolar, las y los estudiantes actúan con mayor libertad y en muchas ocasiones, se encuentran compartiendo en el patio escolar, con poca o ninguna supervisión de las y los docentes. Con ello, podría suceder, tal y como lo señala Muñoz (2003, p. 44), "que ocurran abusos o malos tratos entre los niños o conductas que los pongan en riesgo. Es necesario que padres y autoridades escolares expliquen a las niñas y a los niños que esta libertad exige responsabilidad, prudencia y respeto". Por tanto, es preciso que la y el docente tome conciencia de la importancia que tiene el proceso de supervisión del recreo escolar, como un proceso de acompañamiento que permita 
a docentes y estudiantes sentir que pueden compartir las actividades de socialización que se desarrollan; así como intervenir en aquellas diferencias de criterio o en aquellas situaciones que se podrían tornar en comportamientos violentos entre estudiantes.

El estar presente en el espacio y el tiempo donde se podrían presentar problemas de violencia entre estudiantes, permitiría al docente implementar acciones que accedan, en ese momento, a solucionar entre todas las partes los conflictos, desde una visión más creativa. Asimismo, la supervisión del recreo le permite al docente conocer a sus estudiantes en un espacio abierto, de mayor libertad, donde a través de los juegos y las interacciones sociales con sus compañeras y compañeros se comporten tal y como son. Podrá reconocer las dificultades que puedan tener para formar parte de otros grupos de pares, para integrarse a las actividades que se desarrollan, para conversar o compartir y resolver los problemas que se le presentan. En fin, el recreo podría convertirse en un espacio escolar que ofrezca al docente la oportunidad de acercarse más al estudiante y, por ende, colaborar eficientemente en su desarrollo integral. Desde esta perspectiva, el estudiante podrá contar con un adulto que pueda ayudarlo a resolver los problemas que se le presenten. De igual manera, podrá encontrar en la y el docente, tal vez, un compañero de juegos o quizá alguien que pueda simplemente escuchar aquellas cosas que vive diariamente en la escuela o el hogar y que, quizá, no puede o no desea compartir con otra persona.

En este proceso de supervisión del recreo, resulta importante que la administración de la escuela organice este proceso de manera que el personal docente puede llevar a cabo esta labor. Pero, también pueda de forma alternada contar con un tiempo para realizar algunas actividades propias, como podría ser: tomar café, conversar con sus colegas, realizar alguna llamada telefónica urgente, prepara algún material didáctico, entre otras actividades.

\section{Conclusiones}

Es importante reseñar en primera instancia que el personal docente y administrativo que labora en esta escuela, está totalmente consciente del fenómeno de violencia física, verbal, psicológica y sexual que se suscita entre estudiantes durante los recreos. Las observaciones y las entrevistas a profundidad realizadas a docentes, directora de la institución permitieron corroborar la permanencia de comportamientos violentos entre estudiantes en los recreos, a pesar del proceso de supervisión del recreo por parte del personal docente que implementa la institución educativa. Precisamente uno de los hallazgos encontrados durante el desarrollo del estudio, está relacionado con el proceso de supervisión de los recreos por parte del personal docente y administrativo de la escuela. Algunas docentes realizaban a cabalidad la función de supervisión, pero otras y otros en cambio cumplieron a "medias" el proceso; en otras palabras se logró observar que la mayoría del personal docente realmente hacía acto de presencia en los sitios asignados, pero se dedicaban a conversar, tomar café, entre otras cosas y no estaban atentos a los acontecimientos que se suscitaban. Ante esta situación se logró observar cómo en muchas ocasiones ocurrían en los espacios estipulados por la escuela para el desarrollo del recreo, juegos y otras actividades de interacción personal que suscitaban comportamientos violentos tanto físicos, verbales, psicológicos y de maltrato sexual, y las y los docentes no detectaban estos comportamientos entre estudiantes. Al entrevistar a las y los docentes acerca 
de si consideraban que les correspondía como parte de la labor docente la supervisión del recreo, sus respuestas evidenciaron que aceptan esa labor porque se les obliga, pero que realmente pareciera que no existe un pleno consenso en la realización de esta tarea. Podría interpretarse que el rol que se les asigna es percibido como una imposición y por lo tanto, se lleva a cabo sin la convicción de la importancia que podría tener para la convivencia de las y los estudiantes el contar con la presencia y participación activa del docente en las actividades que se ejecutan durante el recreo. Se podría suponer que el personal docente percibe que está perdiendo un período posterior al proceso de enseñanza donde este aprovechaba ese lapso de tiempo para descansar, tomar su café y algunas otras actividades generalmente ligadas con el proceso escolar. Las entrevistas en profundidad permitieron evidenciar que en las respuestas del personal docente se contraponen dos percepciones respecto al proceso de supervisión del recreo, en estas se identifica una oposición del tipo sí - no donde se afirma y niega de forma simultánea la función de supervisar el recreo como una responsabilidad más de la labor docente. Pareciera que existen sentimientos encontrados que marcan el rol que desempeña el docente durante el proceso de supervisión del recreo, por un lado temen faltar a la responsabilidad que les asignó la dirección de la escuela, pero por otro parte, se sienten abrumados ante la imposibilidad de contar con un espacio que les permita descansar, satisfacer sus necesidades básica e interactuar socialmente con sus colegas durante este breve lapso de tiempo.

Otro hallazgo encontrado en este proceso de investigación, tiene que ver con el tipo de medidas que adopta la escuela para resolver los comportamientos violentos que se suscitan entre estudiantes durante el recreo. En el caso particular del personal docente se encontró que respecto a la intervención ante los conflictos que se presentan, se tiende al empleo de modelos punitivos y relacionales. Existe una marcada tendencia por parte de las docentes al empleo del modelo relacional para tratar de resolver los conflictos a través del diálogo entre victimario y víctima. Sin embargo, también se emplea el modelo punitivo, el cual se convierte en el recurso más empleado por el personal docente para sancionar los problemas relacionados con los comportamientos violentos durante los recreos, a través de la boleta o informe al hogar y en su empleo el docente tiene presente que cuenta con el apoyo de la de dirección de la escuela. A pesar de que en las entrevistas al personal docente y administrativo, los mismos fueron enfáticos al manifestar que este tipo de sanción no es la más conveniente de emplear pero que sin embargo, es un instrumento que permite resolver de forma fácil y obligada de resolver los problemas de violencia.

\section{Referencias}

Arellano, N. (2007). La violencia escolar y la prevención del conflicto. Revista ORBIS, 7, 23-45. Recuperado de http://www.revistaorbis.org.ve/7/Art2.pdf

Artavia, J.M. (2011). Juegos e interacción social en los recreos y su relación con los comportamientos violentos: El caso de las y los estudiantes de VI año de una escuela de la Dirección Regional de Educación de Occidente. (Tesis inédita de doctorado). Sistema de Estudios de Posgrado, Universidad Estatal a Distancia. San José, Costa Rica. 
Barreiro, T. (2010). Conflictos en el aula. Buenos Aires, Argentina: Novedades Educativas.

Brawer, M. (2006). Hacia la construcción del conocimiento que oriente el diseño de políticas públicas. Violencia en las escuelas. Recuperado de http://www.emprendimientos.org.ar/index archivos/3nota8.pdf

Carbonell, J.L. \& Peña, A.I. (2001). El despertar de la violencia en las aulas. La convivencia en los centros educativos. Madrid: CCS.

Chaves, A.L. (2013). Una mirada a los recreos escolares. El sentir y pensar de los niños y niñas. Revista Electrónica Educare 17 (1), 67-87. Recuperado de http:// www.revistas. una.ac.cr/index.php/EDUCARE/article/view/4973

Dean, W. (1995). Prevención de la violencia en las escuelas (School Violence Prevention). Recuperado de Eric Clearinhouse on educational Management Eugene OR. ERIC Digest 94.

Muñoz, C. (2003). El recreo escolar en el sexto grado ijuego o violencia? (Tesis de licenciatura Universidad Pedagógica Nacional) Recuperado de http://biblioteca.ajusco.upn.mx/pdf/20416.pdf

Olweus, D. (1998). Conductas de acoso y amenaza entre escolares. Madrid: Morata.

Osorio, F. (2006). Violencia en las escuelas. Un análisis desde la subjetividad. Buenos Aires: Centro de Publicaciones Educativas y Material Didáctico.

Programa de capacitación para administradores de la educación. Ministerio de Educación Pública. (1991). Métodos y técnicas de supervisión educativa. San José, Costa Rica: Departamento de Publicaciones Ministerio de Educación Pública.

Romera, E., Ortega, R. y Monks, C. (2008). Impacto de la actividad lúdica en el desarrollo de la competencia social. Internacional Journal of Psychology and Psychological Therapy, 2, 193-202. Recuperado de http://redalyc.uaemex.mx/src/inicio/ArtdfRed.jsp?iCve=56080205

Torrego, J.C. (2006). Modelo integrado de mejora de la convivencia. Estrategias de mediación y tratamiento de conflictos. Barcelona: Graó.

Torres, J. (2006). Profesoras y profesores en el ojo del huracán. Foro de educación, (7 y 8), 81-102. Recuperado de http://www.forodeeducacion.com/numeros7 8/008.pdf

Vernieri, M.J. (2010). Violencia escolar ¿iSe podrá hacer algo? Buenos Aires: Bonum. Recuperado de http://www.terras.edu.ar/jornadas/94/biblio/94El-rol-docente-en-relacion-con-laviolencia-escolar.pdf 